\title{
Indeks Kepuasan Masyarakat Terhadap Pelayanan Publik Pada Dinas Kependudukan Dan Pencatatan Sipil Kabupaten Sumedang
}

\author{
Dhesti Widya Nurhasanah Ningrum¹, Irma Hermayanty ${ }^{2}$
}

\begin{abstract}
ABSTRAK
Pelayanan publik yang diberikan oleh organisasi pemerintah berpengaruh terhadap kualitas pelayanan yang dirasakan oleh masyarakat. Oleh karena itu, organisasi pemerintah dalam hal ini Dinas Kependudukan dan Pencatatan Sipil Kabupaten Sumedang yang melalui Bidang Pendaftaran Penduduk perlu memberikan pelayanan yang baik kepada masyarakat. Kurang nyamanannya ruang tunggu yang dimiliki dapat mempengaruhi kualitas pelayanan yang di rasakan oleh masyarakat pengguna jasa. Selain itu, masyarakat masih belum memahami mengenai alur pelayanan yang ada di Dinas Kependudukan dan Pencatatan Sipil Kabupaten Sumedang. Adapun tujuan dari penelitian ini adalah mengetahui nilai indeks kepuasan masyarakat terhadap pelayanan publik pada Dinas Kependudukan dan Pencatatan Sipil Kabupaten Sumedang. Metode yang digunakan dalam penelitian ini adalah penelitian kuantitaf dengan menggunakan pendekatan deskriptif analisis, sehubungan data yang akan dipelajari adalah data yang diambil dari populasi tersebut dengan menggunakan rumus IKM (Indeks Kepuasan Masyarakat) yang terdiri dari 14 unsur pelayanan. Hasil dari penelitian menunjukkan bahwa secara keseluruhan pelayanan yang diberikan oleh Dinas Kependudukan dan Pencatatan Sipil Kabupaten Sumedang baik itu bidang sebesar 75,615 yang berada dalam kategori Baik. Nilai untuk rata-rata pada per unsur pelayanan sebagai berikut: unsur prosedur pelayanan sebesar 3.140, unsur persyaratan pelayanan sebesar 3.027, unsur kejelasan petugas pelayanan sebesar 3.040, unsur kedisiplinan petugas pelayanan sebesar 3.033, unsur tanggung jawab petugas pelayanan sebesar 3.020, unsur kemamuan petugas pelayanan sebesar 3.040, unsur kecepatan pelayanan sebesar 3.007, unsur keadilan mendapatkan pelayanan sebesar 3.020, unsur kesopanan dan keramahan petugas sebesar 3.027, unsur kewajaran biaya pelayanan sebesar 3.047, unsur kepastian biaya pelayanan sebesar 3.027, unsur kepastian jadwal pelayanan sebesar 3.047, unsur kenyamanan lingkungan sebesar 3.053, dan unsur keamanan pelayana sebesar 3.073.
\end{abstract}

\section{ABSTRACT}

Public services provided by government organizations affect the quality of service perceived by the community. Therefore, government organizations in this case Dinas Kependudukan dan Pencatatan Sipil Kabupaten Sumedang through Bidang Pendaftaran Penduduk need to provide good service to the community. The lack of comfort in the

\footnotetext{
${ }^{1}$ Dosen Ilmu Administrasi Negara. STIA Sebelas April Sumedang. Email: dhe_widy@yahoo.com

${ }^{2}$ Dosen Ilmu Administrasi Negara. STIA Sebelas April Sumedang. Email: irmaharyanty79@gmail.com
} 
waiting room that is owned can affect the quality of service that is felt by the service user community. In addition, the community still does not understand the service flow in the Dinas Kependudukan dan Pencatatan Sipil Kabupaten Sumedang. The purpose of this study was to determine the value of satisfaction of indexs society on Dinas Kependudukan dan Pencatatan Sipil Kabupaten Sumedang. The method used in this study is quantitative research using a descriptive analysis approach, in connection with the data to be studied is data taken from the population using the formula of IKM (Indeks Kepuasan Masyarakat/ Satisfaction Index of Society) consisting of 14 elements of service. The results of the research indicate that the overall service provided by the Dinas Kependudukan dan Pencatatan Sipil Kabupaten Sumedang is 75.615 which are in the category of Good, which are in the category of Good. The value for the average on each service element is as follows: 3.140 for service procedure element, the service requirement element is 3,027, the clarity of the service officer is 3,040, the disciplinary element of the service officer is 3,033, the service responsibility element is 3,020, is 3,040, element of service speed is 3,007, element of justice to get service is 3,020, politeness element and hospitality officer is 3,027, service cost element is 3,047, element certainty service cost is 3,027, element certainty service schedule is 3,047, and the security element of the service is 3,073.

Keyword : Publick management, public service, society statisfaction index

\section{Pendahuluan}

Berdasarkan Keputusan MENPAN Nomor 25 Tahun 2014, bahwa yang dimaksud dengan pelayanan publik adalah segala kegiatan pelayanan yang dilaksanakan oleh penyelenggara pelayanan publik sebagai upaya pemenuhan kebutuhan penerima pelayanan maupun pelaksanaan ketentuan peraturan perundang-undangan. Sehingga hakekatnya kewajiban dari aparatur pe-merintah adalah memberikan pelayanan prima kepada seluruh lapisan masyarakat.

Kabupaten Sumedang sebagai Pemerintah Daerah memiliki kewajiban untuk memberikan pelayanan yang prima kepada masyarakat dalam segala sektor pemerintahan tidak terkecuali pelayanan yang diberikan oleh Dinas Kependudukan dan Catatan Sipil dalam hal pendaftaran penduduk. Pelayanan publik yang diberikan oleh bidang pendaftaran penduduk diantarannya pem-buatan E-KTP, Kartu Keluarga, dan lain sebagainya. Petugas pelayanan dituntut untuk dapat bersikap ramah dan sopan, cepat dan tangkas dalam memberikan pelayanan langsung kepada masyarakat.
Pelayanan prima yang diberikan oleh petugas pelayanan bidang pendaftaran penduduk sangat berpengaruh terhadap kualitas pelayanan yang dirasakan oleh masyarakat yang dilayani. Kualitas pelayanan merupakan salah satu faktor penentu dalam keberhasilan pemberian pelayanan oleh Dinas/Instansi maupun petugas pelayanan. Semakin masyarakat merasa puas dilayani maka semakin berkualitas pelayanan yang diberikan oleh Dinas/Instansi atau petugas pelayanan kepada masyarakat.

Hal yang harus diperhatikan di dalam standar pelayanan publik berdasarkan Keputusan MENPAN Nomor 25 Tahun 2004 meliputi prosedur pelayanan, waktu pe-nyelesaian, biaya pelayanan, produk pe-layanan, sarana prasarana dan kompetensi petugas pemberi pelayanan.

Berdasarkan uraian diatas maka perumusan masalah dalam penelitian ini adalah "Berapakah nilai indeks kepuasan masyarakat terhadap pelayanan publik pada Dinas Kependudukan dan Catatan Sipil Kabupaten Sumedang?" sehingga tujuan dari penelitian ini yaitu untuk mengetahui indeks kepuasan masyarakat terhadap pelayanan publik pada Dinas Kependudukan dan Catatan Sipil 
Kabupaten Sumedang. Adapun tujuan dari penelitian ini yaitu untuk mengetahui indeks kepuasan masyarakat terhadap pelayanan publik pada Dinas Kependudukan dan Catatan Sipil Kabupaten Sumedang.

\section{Kajian Teori}

Pelayanan publik adalah segala kegiatan pelayanan yang dilaksanakan oleh penyelenggara pelayanan publik sebagai upaya pemenuhan kebutuhan penerima pelayanan maupun pelaksanaan ketentuan peraturan perundang-undangan (KEPMEN-PAN Nomor 25 Tahun 2014).

Menurut Ratminto dan Atik Septi (2010:

5) pelayanan publik atau pelayanan umum adalah:

"Segala bentuk jasa pelayanan, baik dalam bentuk barang publik maupun jasa publik yang pada prinsipnya menjadi tanggung jab dan dilaksanakan oleh Instansi Pemerintah di Pusat, di Daerah, dan di lingkungan Badan Usaha Milik Negara atau Badan Usaha Milik Daerah, dalam rangka upaya pemenuhan kebutuhan masyarakat maupun dalm rangka pelaksanaan ketentuan perundang-undangan”.

Kepuasan pelayanan adalah hasil pendapat dan penilaian masyarakat terhadap kinerja pelayanan yang diberikan oleh aparatur penyelengara pelayanan publik. Unsur pelayanan adalah faktor atau aspek yang terdapat dalam penyelenggaraan pelayanan kepada masyarakat.

Pelayanan publik oleh birokrasi publik merupakan salah satu perwujudan dari fungsi aparatur negara sebagai abdi masyarakat disamping sebagai abdi negara. Pelayanan publik oleh birokrasi publik dimaksudkan untuk mensejahterakan rakyat. Sehingga pelayanan publik dapat diartikan sebagai pemberian layanan (melayani) keperluan orang atau masyarakat yang mempunyai kepentingan pada organisasi itu sesuai dengan aturan pokok dan tata cara yang telah ditetapkan (Moleong, 2004: 97).

Terdapat tiga bentuk dasar pela-yanan, yaitu layanan dengan lisan, layanan dengan tulisan dan layanan melalui perbuatan. Adapun penjelasan mengenai tiga bentuk dasar pelayanan tersebut sebagai berikut:

1. Layanan dengan lisan diberikan oleh personil yang bertugas memberikan layanan informasi dari bidang lainnya yang tugasnya memberikan penjelasan kepada pihak yang memerlukan. Dalam suatu organiasasi, layanan ini biasanya diberikan pada bagian Hubungan Masyarakat atau yang semacamnya. Beberapa syarat yang dipenuhi dalam layanan lisan ini agar bisa berhasil sesuai dengan yang diharapkan adalah sebagai berikut :

a. Mampu memberikan penjelasan yang diperlukan dengan lancar, singkat dan jelas sehingga memuaskan para pengguna jasa

b. Bersikap sopan dan ramah

c. Dengan bersikap sopan tidak melayani orang-orang yang sekedar ingin ngobrol

d. Tidak membuang-buang waktu dengan mengobrol atau membicarakan hal-hal yang tidak ada manfaatnya

2. Layanan dengan tulisan merupan bentuk layanan yang paling efisien dan paling banyak digunakan. Dimana layanan ini bisa diberikan dalam jarak jauh. Suatu hal yang diperhatikan dalam pemberian layanan tulisan adalah kecepatan pengelolaan masalah dan proses penyelesaiannya. Layanan tulisan terdiri dari dua kelompok, yaitu:

a. Layanan berupa petunjuk/informasi dan yang sejenis dengan itu yang ditunjukkan kepada orang-orang yang berkepentingan

b. Layanan berupa reaksi atau permohonan, keluhan, laporan, ataupun pemberitahuan

3. Layanan dengan perbuatan banyak dilakukan oleh petugas-petugas tingkat menengah kebawah dengan keahlian atau keterampilan yang memadai. Layanan ini sering dibarengi dengan layanan lisan. Layanan perbuatan memiliki spesifikasi tertentu yang membedakannya dengan layanan lisan, yaitu orang tidak hanya membutuhkan penjelasan tetapi juga memerlukan perbuatan atau tindakan atau hasil perbuatan.

Kepuasan pelanggan menurut Gotleb, Grewal dan Brown (dalam Tjiptono, 2004: 147) merupakan respon afektif terhadap 
pengalaman melakukan konsumsi yang spesifik, lebih lanjut menurut Tse dan Wilton (dalam Tjiptono, 2004: 146) disebutkan bahwa kepuasan atau ketidakpuasan pelanggan adalah respon pelanggan terhadapevaluasi ketidaksesuaian yang dirasakan antara harapan sebelumnya dan kinerja aktual produk setelah pemakainnya.

Zeithaml dalam Mukarom (2015: 109) mengemukakan sepuluh dimensi yang harus diperhatikan dalam tolak uku kualitas pelayanan publik, yaitu:

1. Tangible, terdiri dari fasilitas fisik, peralatan, personel dan komunikasi;

2. Realiable, terdiri atas kemampunan unit pelaynan dalam menciptakan pelayanan yang dijanjikan dengan tepat;

3. Responsiveness, kemampuan untuk membantu konsumen bertanggung jawab terhadap kualitas pelayanan yang diberikan;

4. Competence, tuntutan yang dimilikinya, pengetahuan dan keterampilan yang baik oleh aparatur dalam memberikan pela-yanan;

5. Courtesy, sikap atau perilaku ramah, bersahabat, tanggap terhadap keinginan masyarakat serta mau melakukan kontak atau hubungan pribadi;

6. Credibility, sikap jujur dalam setiap upaya untuk menarik kepercayaan masyarakat;

7. Security, jasa pelayanan yang diberikan harus bebas dari berbagai bahaya dan risiko;

8. Access, terdapat kemudahan untuk mengadakan kontak dan pendekatan;

9. Communication, kemauan pemberi pelayanan untuk mendengarkan suara, keinginan atau aspirasi pelanggan, sekaligus kesediaan untuk selallu menyampaikan informasi baru kepada masyarakat; dan

10. Understanding the costumer, melakukan segala usaha untuk mengetahui kebutuhan pelanggan.

Untuk mengukur nilai indeks kepuasan masyarakat menggunakan 14 indikator pengukuran indeks kepuasan masyarakat yang telah ditetapakan oleh Kementrian Pendayagunaan Aparatur Negara dan Reformasi Birokrasi Republik Indonesia dalam bentuk KEPMENPAM Nomor 25 Tahun 2014 tentang Pedoman Penyusunan Indeks Kepuasan
Masyarakat unit Pelayanan Instansi Pemerintah terdiri dari :

a. Prosedur pelayanan;

b. Persyaratan Pelayanan;

c. Kejelasan petugas pelayanan;

d. Kedisiplinan petugas pelayanan;

e. Tanggung jawab petugas pelayanan;

f. Kemampuan petugas pelayanan;

g. Kecepatan pelayanan;

h. Keadilan mendapatkan pelayanan;

i. Kesopanan dan keramahan petugas;

j. Kewajaran biaya pelayanan;

k. Kepastian biaya pelayanan;

1. Kepastian jadwal pelayanan;

m. Kenyamanan lingkungan;

n. Keamanan Pelayanan.

\section{Metode Penelitian}

Pada penelitian ini, bentuk metode yang akan digunakan adalah bentuk pendekatan penelitian deskriptif analisis, sehubungan data yang akan dipelajari adalah data yang diambil dari populasi tersebut. Yaitu agar ditemukan kejadian-kejadian relatif, distribusi dan hubungan-hubungan antar komponen. Menurut Iskandar (2005:174) Penelitian deskriptif adalah penelitian yang ada hubungannya dengan pemaparan suatu penomena atau hubungan antara dua atau lebih fenomena, dan metode ini sering kali menggunakan teknik survey.

Populasi pada penelitian ini adalah masyarakat pengguna layanan pada Bidang Pendaftaran Penduduk dan Bidang Akte di Dinas Kependudukan dan Catatan Sipil Kabupaten Sumedang. Adapun untuk jumlah responden minimal 150 orang yang dipilih secara acak, dengan dasar ("jumlah unsur" +1$) \times 10=(14+$ 1) $\mathrm{x} 10=150$ responden. Pada penelitian ini jumlah respondennya sesuai dengan ketentuan jumlah responden minimal yaitu sebanyak 150 orang.

Data yang dikumpulkan dalam penelitian ini adalah data primer dan data sekunder. Data primer yaitu data yang diperoleh langsung dari responden sesuai dengan kebutuhan informasi yang dituangkan dalam pernyataan/pertanyaan terstruktur. Data skunder yaitu data yang diperoleh secara tidak langsung dari responden 
yang menunjang pembahasan hasil penelitian dengan cara melakukan studi kepustakaan, studi lapangan dan observasi.

Teknik pengumpulan data yang digunakan dalam penelitian ini adalah :

\section{Studi Dokumentasi}

Suatu upaya memperoleh keterangan ilmiah dari sumber-sumber tertulis yang berkaitan dengan masalah yang diteliti, seperti undangundang dan peraturan daerah.

\section{Studi Lapangan}

\section{a) Observasi}

Pengamatan langsung ke lokasi penelitian untuk melihat dan mencatat kegiatan yang berhubungan dengan masalah yang akan diteliti.

\section{b) Angket}

Teknik ini dilakukan dengan cara menyebarkan daftar pernyataan tertutup kepada responden. Daftar pertanyaan yang diajukan telah disiapkan berbagai alter-natif jawaban yang telah diarahkan dan disesuaikan dengan pokok per-maslahan dan tujuan penelitian.

Untuk mendapatkan hasil yang objektif dalam penelitian, maka data yang didapatkan akan dianalisis secara kuantitatif. Adapun cara menganalisis data tersebut sevagai berikut:

$\begin{gathered}\text { Bobot nilai } \\ \text { rata-rata } \\ \text { tertimbang }\end{gathered} \quad=\frac{\text { Jumlah Bobot }}{\text { Jumlah Unsur }}=\frac{1}{14}=0,071$

1. Nilai IKM dihitung dengan menggunakan "nilai rata-rata tertimbang" masing-masing unsur pelayanan. Dalam penghitungan ndeks kepuasan masyarakat terdapat 14 unsur pelayanan yang dikaji, setiap unsur pelayana memiliki rumus sebagai berikut:

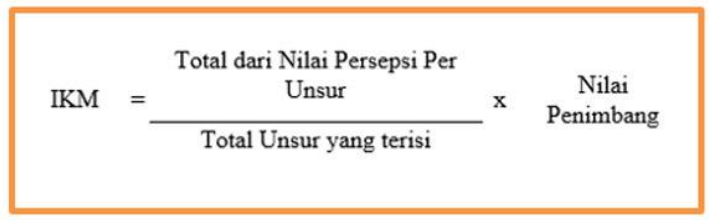

3. Untuk memperoleh nilai IKM unit pelayanan digunakan pendekatan nilai rata-rata tertimbang dengan rumus sebagai berikut:

4. Untuk memudahkan interprestasi terhadap penilaian IKM yaitu antara 25-100 maka hasil penilaian tersebut di atas dikonversikan dengan nilai dasar 25, dengan rumus sebagai berikut:

\section{IKM Unit Pelayanan x 25}

Mengingat unit pelayanan mempunyai karakteristik yang berbeda-beda, maka setiap unit pelayanan dimungkinkan untuk:

a. Menambah unsur yang dianggap relevan;

b. Memberikan bobot yang berbeda terhadap 14 unsur yang dominan dalam unit pelayanan, dengan catatan jumlah bobot seluruh unsur tetap 1 .

\section{Tabel 1}

Nilai Persepsi, Interval IKM, Interval Konversi IKM, Mutu Pelayanan dan Kinerja Unit pelayanan

\begin{tabular}{|c|c|c|c|c|}
\hline $\begin{array}{c}\text { Nilai } \\
\text { Persepsi }\end{array}$ & $\begin{array}{c}\text { Nilai } \\
\text { Interval } \\
\text { IKM }\end{array}$ & $\begin{array}{c}\text { Nilai Interval } \\
\text { Konversi IKM }\end{array}$ & $\begin{array}{c}\text { Mutu } \\
\text { Pelayanan }\end{array}$ & $\begin{array}{c}\text { Kinerja } \\
\text { Unit } \\
\text { Pelayanan }\end{array}$ \\
\hline 1 & $1,00-1,75$ & $25-43,75$ & D & $\begin{array}{c}\text { Tidak } \\
\text { Baik }\end{array}$ \\
\hline 2 & $1,76-2,50$ & $43,76-62,50$ & $\mathrm{C}$ & $\begin{array}{c}\text { Kurang } \\
\text { Baik }\end{array}$ \\
\hline 3 & $2,51-3,25$ & $62,51-81,25$ & $\mathrm{~B}$ & \begin{tabular}{c} 
Baik \\
\hline 4
\end{tabular} \\
\hline $3,26-4,00$ & $81,26-100,00$ & $\mathrm{~A}$ & $\begin{array}{c}\text { Sangat } \\
\text { Baik }\end{array}$ \\
\hline
\end{tabular}




\section{Pembahasan}

\section{Nilai Indeks Kepuasan Masyarakat}

Hasil perhitugan yang dilakukan terhadap 14 indikator atau unsur pelayanan publik di Dinas Ke-pendudukan dan Pencatatan Sipil Kabupaten Sumedang berdasarkan Keputuasan Menteri Penda-yagunaan Aparatur Negara No. 25/M.PAN/2/2014 tentang Pedoman Penyusunan Indeks Kepuasan Masyarakat unit Pelayanan Instansi Pemerintah. Indikator-indikator tersebut terdiri dari prosedur pelayanan, persyaratan pelayanan, kejelasan petugas pelayanan, kedisiplinan petugas pelayanan, tanggung jawab petugas pelayanan, kemampuan petugas pelayanan, kecepatan pelayanan, keadilan mendapatkan pelayanan, kesopanan dan keramahan petugas, kewajaran biaya pelayanan, kepastian biaya pelayanan, kepastian jadwal pelayanan, kenya-manan lingkungan dan keamanan lingkungan.

Dalam penghitungan Indeks Kepuasan Masyarakat (IKM) terdapat 14 unsur pelayanan yang dikaji, setiap unsur pelayanan memiliki penimbang yang sama yaitu 0,071 yang didapat dari jumlah bobot dibagi jumlah unsur. Berdasarkan data yang dihimpun, ke-14 indikator memiliki nilai unsur yang berbeda diantaranya prosedur pelayanan memiliki nilai unsur 3,14, persyaratan pelayanan memiliki nilai unsur 3,027, kejelasan petugas pelayanan memiliki nilai unsur 3,04, kedisiplinan petugas memiliki nilai unsur 3,033, tanggung jawab petugas memiliki nilai unsur 3,02, kemampuan petugas pelayanan memiliki nilai unsur 3,04, kecepatan pelayanan memiliki unsur 3,07, keadilan dalam mendapatkan pelayanan memiliki nilai unsur 3,02, kesopanan dan keramahan petugas memiliki nilai unsur 3,027, kewajaran biaya pelayanan memiliki nilai unsur 3,047, kepastian biaya pelayanan memiliki nilai unsur 3,027, kepastian jadwal pelayanan memiliki nilai unsur 3,047, kenyamanan lingkungan memiliki nilai unsur 3,053, keamanan pelayanan memiliki nilai unsur 3,073.

Berdasarkan nilai yang didapatkan dari masing-masing unsur maka diperoleh nilai indeks kepuasan masyarakat sebagai berikut:

Tabel 2

Hasil Indeks Kepuasan Masyarakat Terhadap Pelayanan Publik di Dinas Kependudukan dan Pencatatan Sipil Kabupaten Sumedang

\begin{tabular}{|c|c|c|c|c|c|c|c|c|c|c|c|c|c|c|c|}
\hline \multirow{2}{*}{ Ket } & \multicolumn{14}{|c|}{ Unsur Pelayanan } & \multirow{2}{*}{$\sum$} \\
\hline & U1 & U2 & U3 & U4 & U5 & U6 & U7 & U8 & U9 & U10 & U11 & U12 & U13 & U14 & \\
\hline $\begin{array}{l}\text { Jml } \\
\text { Nilai per } \\
\text { unsur }\end{array}$ & 471 & 454 & 456 & 455 & 453 & 456 & 451 & 453 & 454 & 457 & 454 & 457 & 458 & 461 & 6390 \\
\hline NRR & $\begin{array}{c}3,1 \\
40 \\
\end{array}$ & $\begin{array}{l}3,0 \\
27 \\
\end{array}$ & $\begin{array}{c}3,0 \\
40 \\
\end{array}$ & $\begin{array}{l}3,0 \\
33 \\
\end{array}$ & $\begin{array}{c}3,0 \\
20 \\
\end{array}$ & $\begin{array}{c}3,0 \\
40 \\
\end{array}$ & $\begin{array}{l}3,0 \\
07 \\
\end{array}$ & $\begin{array}{l}3,0 \\
20 \\
\end{array}$ & $\begin{array}{l}3,0 \\
27 \\
\end{array}$ & $\begin{array}{l}3,0 \\
47 \\
\end{array}$ & $\begin{array}{l}3,0 \\
27 \\
\end{array}$ & $\begin{array}{c}3,0 \\
47 \\
\end{array}$ & $\begin{array}{l}3,0 \\
53 \\
\end{array}$ & $\begin{array}{c}3,07 \\
3\end{array}$ & \\
\hline $\begin{array}{l}\text { NRR } \\
\text { Tertimb } \\
\text { ang }\end{array}$ & $\begin{array}{l}0,2 \\
23\end{array}$ & $\begin{array}{c}0,2 \\
15\end{array}$ & $\begin{array}{c}0,2 \\
16\end{array}$ & $\begin{array}{c}0,2 \\
15\end{array}$ & $\begin{array}{c}0,2 \\
14\end{array}$ & $\begin{array}{c}0,2 \\
16\end{array}$ & $\begin{array}{c}0,2 \\
13\end{array}$ & $\begin{array}{l}0,2 \\
14\end{array}$ & $\begin{array}{c}0,2 \\
15\end{array}$ & $\begin{array}{c}0,2 \\
16\end{array}$ & $\begin{array}{c}0,2 \\
15\end{array}$ & $\begin{array}{c}0,2 \\
16\end{array}$ & $\begin{array}{l}0,2 \\
17\end{array}$ & $\begin{array}{c}0,21 \\
8\end{array}$ & 3,025 \\
\hline IKM & & & & & & & & & & & & & & & \\
\hline
\end{tabular}

Dengan demikian nilai indeks pelayanan hasilnya dapat disimpulkan sebagai berikut :

a. Nilai IKM setelah dikonversi = nilai indeks x nilai penimbang $=3,025 \times 25$ $=75,615$

b. Dengan melihat tabel (Nilai Persepsi, Interval IKM, Interval Konversi IKM) maka dapat diketahui bahwa dengan nilai
IKM sebesar 75,615, hal ini menunjukkan mutu pelayanan dan kinerja pelayanan dikatakan baik.

\section{Hasil Kepuasan Masyarakat Berda-sarkan Karakteristik Responden}

Untuk memperjelas hasil kepuasan masyarakat kepada pelayanan publik di Dinas 
Kependudukan dan Pencatatan Sipil Kabupaten Sumedang, maka dilakukan perhitunga kepuasan masyarakat berdasarkan karakteristik responden yang terdiri dari jenis kelamin, umur, jenis pekerjaan, dan tingkat pendidikan.

Dalam perhitungan kepuasan masyarakat berdasarkan karaketristik responden masing-masing karakteristik nilai tertimbang yang sama dengan perhitungan indeks kepuasan masyarakat sebesar 0,071. Hasil per-hitungan untuk karakteristik responden berdasarkan jenis kelamin memiliki nilai unsur sebesar 3,02, berdasarkan umur memiliki nilai unsur sebesar 3,03 , berdasarkan pekerjaan me-miliki nilai unsur sebesar 3,05, dan berdasarkan pendidikan terakhir memiliki nilai unsur sebesar 3,05.

Berdasarkan nilai unsur dari masinngmasing karaketristik responden tersebut, maka didapat disimpulkan bahwa mutu pelayanan yang diberikan oleh Dinas Kependudukan dan Pencatatan Sipil diperoleh nilai rata-rata sebesar 3,037 sehingga berada dikategori baik.

\section{Simpulan}

Berdasarkan hasil perhitungan indeks kepuasan masyarakat yang telah dibahas di bab pembahasan, maka hasil perhitungan masingmasing unsur pelayanan sebanyak 14 unsur atau indikator didapatkan hasil untuk nilai indeks kepuasan masyarakat yang telah dikonversi sebesar 75,615 dan berada di kategori baik. Adapun nilai rata-rata indeks kepuasan masyarakat yang dikaji berdasarkan karakteristik responden sebesar 3,037 dan berada di kategori baik.

\section{Daftar Pustaka}

Arif, Mts, (2007), Pemasaran Jasa dan Kualitas Pelayanan, Banyumedia, Malang
Atmosudirjo, Prajudi, (1994), Administrasi dan Manajemen Umum, Ghalia Indonesia, Jakarta

Handayaningrat, Soewarno, (1996), Pengantar Studi Ilmu Administrasi dan Manajemen, Gunung Agung, Jakarta

Iskandar, (2005), Manajemen Personalia. Jakarta, Ghalia Putri.

Iskandar, (2014), Kapita Selekta Administrasi Negara dan Kebijakansanaan Publik, Bandung, Puspaga.

Keputusan Menteri Pendayagunaan Aparatur Negara Nomor 25 Tahun 2014 Tentang Pedoman Umum Penyusunan Indeks Kepuasan Masyarakat dan Unit Pelayanan Instansi Pemerintah

Lembaga Administrasi Negara RI, (1998), Sistem Administrasi Negara Republik Indonesia, Jakarta, CV. Haji Mas Agung.

Mitchel, TR dan Lewis. (1990). Organisasi. Jakarta: Gramedia.

Moenir, H.A.S. (2006). Manajemen Pelayanan Umum di Indonesia. Jakarta: Bumi Aksara.

Muhammad, Arni. (2014). Komunikasi

Organisasi. Jakarta: Bumi Aksara.

Mukarom, Zaenal dan Muhibudin Wijaya. (2015). Manajemen Pelayanan Publik. Bandung: CV. Pustaka Setia.

Napitupulu, Paimin dan Thamrin Mandiri. (2008). Ekologi Administrasi Negara. Bandung: Alumni.

Patminto, dan Atik Septi Winarsia. (2010). Manajemen Pelayanan. Yogyakarta: Pustka Pelajar. 
Priabu Tika, Moh. (2012). Budaya Organisasi dan Peningkatan Kinerja Perusahaan. Jakarta: Bumi Aksara.

Prisma. (1996). Administrasi Birokrasi dan Pelayanan Publik. Jakarta: Nimas Multima.

Rencana Strategis Dinas Kependudukan dan Pencatatan Sipil Kabupaten Sumedang Tahun 2015-2018

Sarwoto. (1991). Dasar-dasar Organisasi dan Manajemen. Jakarta: Ghalia Indonesia.

Siagian, Sondang P. (2009). Manajemen Sumber Daya Manusia. Jakarta: Bumi Aksara.

Silalahi, Ulbert. (2009). Studi Tentang Ilmu Administrasi, Konsep, Teori dan Dimensi. Bandung: Sinar Baru Algesindo.

Sinambela, Lajian Poltak dkk. (2006). Reformasi Pelayanan Publik. Jakarta: Bumi Aksara.

Sugiyono. (2005). Metode Penelitian Administrasi. Bandung: Alfabeta.

STIA Sebelas April Sumedang. (2013). Buku Panduan Penulisan Skripsi. Sumedang: STIA.

Syafiie, dkk. (1999). Ilmu Administrasi Publik. Jakarta: Rineka Cipta.

Syamsi, Ibnu. (1994). Pokok-pokok Organisasi dan Manajemen. Jakarta: Rineka Cipta.

Thoha, Miftah. (1997). Perilaku Organisasi, Konsep Dasar dan Aplikasinya. Jakarta: PT. Raya Grafindo Persada.

Thoha, Miftah. (2003). Dimensi-dimensi Prima Ilmu Administtrasi Negara. Yogyakarta: UGM.

Tjiptono, Fandi. (2008). Service Management, Mewujudkan Layanan Prima. Yogyakarta: Andi Office.
Waluyo. (2007). Manajemen Publik (Konsep, Aplikasi dan Implementasinya Dalam Pelaksanaan Otonomi Daerah). Bandung: Mandar Maju.

Westra, Pariatra.dkk (1980). Aneka Sari Ilmu Administrasi. Yogyakarta: Balai Pembinaan Akademi Administrasi Negara. 